\title{
An epidemiological and genetic study of congenital profound deafness in Tunisia (governorate of Nabeul)
}

\author{
S Ben Arab, C Bonaïti-Pellié, A Belkahia
}

\begin{abstract}
An epidemiological and genetic study of profound deafness has been undertaken in the governorate of Nabeul in Tunisia. This paper deals with sensorineural deafness with no associated abnormalities. The prevalence was estimated to be 0.0007 and four clusters could be identified, two of which represent $51 \%$ and $34 \%$ respectively of the total number of cases. Segregation analysis performed in 29 pedigrees containing 415 subjects with 129 affected cases provided evidence for simple recessive inheritance with no sporadic cases.
\end{abstract}

The causes of profound deafness are various and genetic factors are known to play an important role in most diseases. ${ }^{12}$ Apart from a preliminary study in the governorate of Bizerte, ${ }^{3}$ no epidemiological and genetic study of deafness had previously been undertaken in Tunisia. Because of the high frequency of consanguineous matings, which may favour local aggregations, such a study appeared to be of particular interest in Tunisia, both from a purely cognitive point of view and also to draw up guidelines for public health.

A follow up survey of patients in the Department of Otorhinolaryngology of the Rabta (Ernest Conseil) Hospital in Tunis indicated the existence of numerous cases from the governorate of Nabeul and for this reason this genetic and epidemiological study was undertaken there.

Faculté de Médecine, Tunis, Tunisia.

$S$ Ben Arab

Unité de Recherches d'Epidémiologie Génétique, INSERM U155, Château de Longchamp, Bois de Boulogne, 75016 Paris, France.

C Bonaiti-Pellié

Service d'Oto-Rhino-Laryngologie et de Chirurgie Maxilo-Faciale, Hôpital La Rabta, Tunis Tunisia. A Belkahia

Correspondence to Dr Bonaïti-Pellié.

Received for publication 27 February 1989.

Revised version accepted for publication 12 June 1989.
In this paper, we present the results of the study of congenital sensorineural deafness with no associated abnormalities.

\section{Material}

The governorate of Nabeul is located in the northeast of Tunisia (fig 1). The area covers about $2788 \mathrm{~km}^{2}$. The number of inhabitants was estimated as 401405 in 1984 by the National Institute of Statistics. The governorate is divided into 14 districts (fig 2). The rural population has been estimated as $44 \cdot 6 \%$.

The samples of patients and families were collected in two steps. Between 1986 and 1988, 73 patients with sensorineural hearing loss were followed at the Department of Otorhinolaryngology. For 32 of them, it was possible to visit them at their home where the families were interviewed and complete pedigrees established. Affected subjects who had not been ascertained in the first step were carefully examined in the Department of Otorhinolaryngology. An

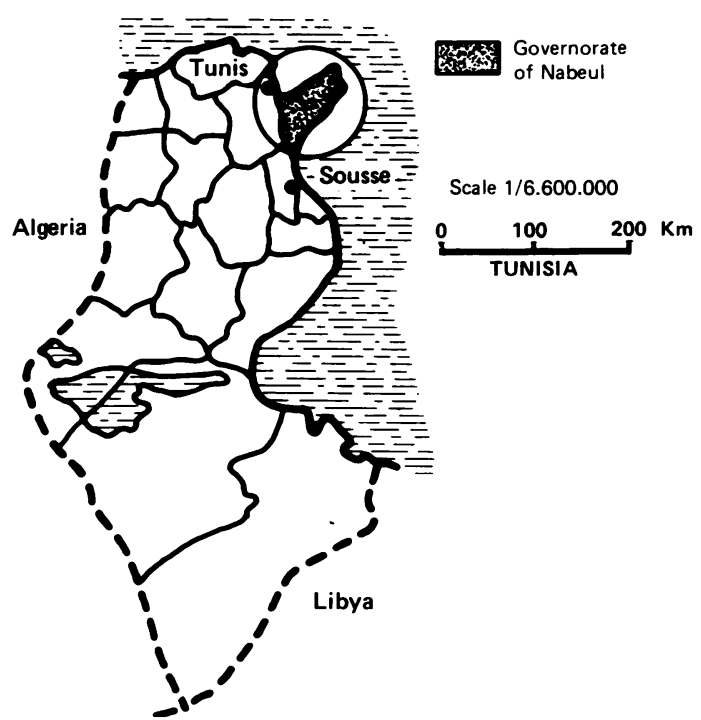

Figure 1 Location of the governorate of Nabeul in Tunisia. 


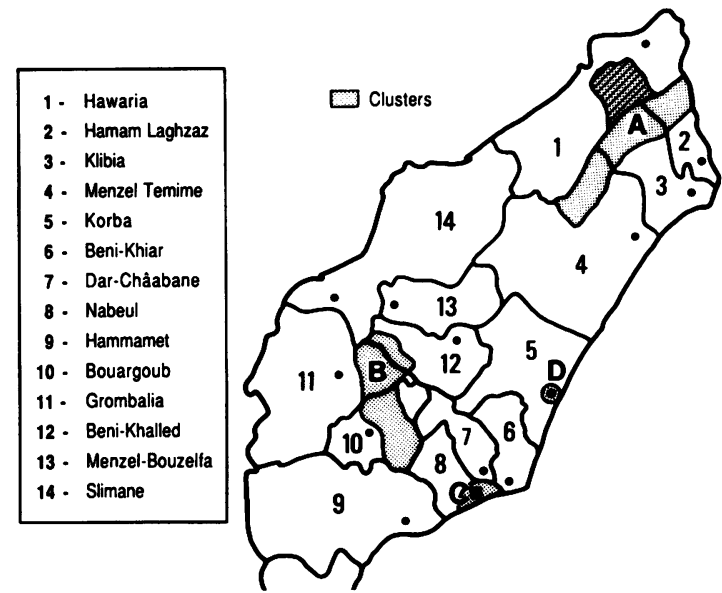

Figure 2 Distribution of the affected subjects in the different sections of the 14 districts of the governorate of Nabeul.

audiometric examination was performed with evoked response audiometry in small children and $x$ ray when necessary.

An inquiry conducted in the villages of the different districts detected another 15 patients who had either never been to a hospital or had been followed in another one (Charles-Nicolle Hospital, Habib Thameur Hospital in Tunis, or the Regional Hospital of the governorate of Sousse). For all these new patients, complete pedigrees were established and they were examined in the Department of Otorhinolaryngology when possible. Two other families were detected through unaffected subjects who asked for genetic counselling because there were several cases of deaf-mutism in their families.

Finally, a total of 195 subjects was examined: 88 of them could be considered as probands, that is, they were already attending the department (73) or were found by systematic inquiry in the villages (15).

\section{Methods}

ESTIMATION OF PREVALENCE

When ascertainment of affected subjects is not complete, it is possible to estimate the frequency $f$ of the disease knowing the number $\mathbf{n}$ of cases ascertained in a given area at a given time, and the probability $\pi$ that an affected case is a proband. If $A$ is the number of probands collected in this area and living at that time, then $n=A / \pi$. If $N$ is the corresponding population size, then $f=n / N{ }^{7}$

The parameter $\pi$ can be estimated from the distribution of probands among affected cases in sibships with at least two affected cases (multiplex sibships) by the maximum likelihood method. ${ }^{5}$
SEGREGATION ANALYSIS

Since congenital profound deafness with no associated abnormalities is thought to be most often recessively inherited, ${ }^{12}$ segregation analysis was first carried out in nuclear families with unaffected parents in order to compare the estimated segregation frequency $p$ with the expected one of $0 \cdot 25$.

The segregation frequency $p$ was estimated by the maximum likelihood method, allowing for different modes of ascertainment in sibships. ${ }^{6}$ The likelihood for sibships containing at least one proband had to take into account the probability $\pi$ of ascertainment (multiple selection):

$$
P_{1}(p)=\frac{\left(\begin{array}{l}
s \\
r
\end{array}\right) p^{r}(1-p)^{s-r}\left[1-(1-\pi)^{r}\right]}{1-(1-p \pi)^{s}}
$$

where $s$ and $r$ are, respectively, the total number of sibs and the number of affected ones.

The likelihood for sibships with no proband, found by familial investigation, is (truncate selection):

$$
P_{2}(p)=\frac{\left(\begin{array}{l}
s \\
r
\end{array}\right) p^{r}(1-p)^{s-r}}{1-(1-p)^{s}}
$$

For sibships detected through normal subjects who asked for genetic counselling, the selection was considered to be single, since only an important familial aggregation would have led these people to ask for counselling. The likelihood for such sibships is:

$$
P_{3}(p)=\left(\begin{array}{c}
s-1 \\
r-1
\end{array}\right) p^{r-1}(1-p)^{s-r} \text {. }
$$

The likelihood for the whole sample is computed iteratively, using an a priori $p$ value, until the maximum likelihood is reached, providing the estimate of p. Then the frequency of affected children in the offspring of affected subjects (not ascertained through an affected offspring) was compared to the expected one, given the coefficient of kinship between parents.

\section{CONSANGUINITY}

The coefficient of inbreeding was computed for all the probands and was compared to the inbreeding coefficient computed on a random sample representative of the population of the governorate of Nabeul, with the same age distribution as the proband sample, since the inbreeding coefficient tends to decrease in younger generations.

\section{GEOGRAPHICAL DISTRIBUTION OF AFFECTED SUBJECTS}

In order to find possible clusters of the disease, the geographical distribution of affected subjects was studied, first using their place of residence and second according to the origin of their parents. 


\section{Results}

Among the 34 sibships ascertained under multiple selection, there were 17 multiplex ones. Using the distribution of probands among affected cases in these sibships, we could estimate the probability of ascertainment $\pi$ to be $0 \cdot 20$ (SE $0 \cdot 10$ ). The $95 \%$ confidence interval (using the exact truncate binomial distributions with equal probability on each side of the point estimate) was found to be 0.04 to 0.46 .

Among the 88 probands with sensorineural hearing loss, only 55 were retained as having bilateral profound congenital deafness with no associated abnormalities and living in 1984, which was taken as the reference for the population size. So the prevalence can be estimated to be:

$$
\mathrm{f}=55 /(0 \cdot 20 \times 401405)=0 \cdot 0007 \text {. }
$$

Considering the confidence interval for $\pi$, this interval for $f$ is 0.0003 to 0.003 .

The 29 pedigrees contained 415 subjects with 129 affected cases. The number of sibships is given in table 1. An example of a kindred with 25 affected subjects in 10 sibships in three generations is given in fig 3 .

Using the 66 sibships with unaffected parents, the segregation frequency could be estimated as 0.24

Table 1 Distribution of sibships in kindreds with profound deafness according to disease status of parents and type of selection.

\begin{tabular}{llccc}
\hline \multirow{2}{*}{$\begin{array}{l}\text { Disease status } \\
\text { of parents }\end{array}$} & $\begin{array}{l}\text { Type of } \\
\text { selection }\end{array}$ & $\begin{array}{c}\text { No of } \\
\text { sibships }\end{array}$ & Affected & Unaffected \\
\hline Both & Single & 2 & 4 & \multicolumn{2}{c}{ No of sibs } \\
$\quad$ parents & Truncate & 31 & 52 & 116 \\
$\begin{array}{l}\text { unaffected } \\
\text { One affected }\end{array}$ & $\begin{array}{l}\text { Multiple } \\
\text { Marent }\end{array}$ & 33 & 65 & 106 \\
Bothple & Complete & 26 & 1 & 4 \\
$\quad$ affected & Complete & 1 & 4 & 62 \\
Total & & & & 0 \\
\hline
\end{tabular}

(SE 0.03), which fits perfectly with simple recessive inheritance.

There were 26 affected subjects who were not detected through an affected child. Twenty-three of them were not related to their spouse, so their offspring had a probability close to 0 of being affected. They had a total of 56 children, none of whom were affected. The remaining three subjects were married to their first cousin who had a risk of $1 / 4$ of being heterozygous. So, among the six children, $1 / 8 \times 6=0.75$ affected offspring would be expected and three were observed, which is higher, but not significantly so, than the expected number $(p=0.058$, bilateral test using binomial distribution). There was one sibship where both parents were affected. Under recessive inheritance with complete penetrance and no heterogeneity, all the children would be expected to be affected and this was observed (four out of four children affected).

The inbreeding coefficient was computed for the 38 probands where family history was complete, except for two of them whose parents were related but the exact relationship was unknown. The distribution of these affected subjects and the controls according to their inbreeding coefficient is given in table 2 . There is a significantly higher frequency of subjects with a high inbreeding coefficient in the affected group than in the control group $\left(\chi^{2}=31.47\right.$, df $\left.2, \mathrm{p}<0.001\right)$ after removal of the 'unknown' class.

Table 2 Distribution of the 38 probands and the 1596 controls according to inbreeding coefficient.

\begin{tabular}{lcc}
\hline $\begin{array}{l}\text { Inbreeding } \\
\text { coefficient }\end{array}$ & $\begin{array}{c}\text { No of } \\
\text { probands }\end{array}$ & $\begin{array}{c}\text { No of } \\
\text { controls }\end{array}$ \\
\hline 0 & 2 & 795 \\
$<0.0625$ & 11 & 260 \\
$\geqslant 0.0625^{\star}$ & 23 & 458 \\
Unknown & 2 & 83 \\
Total & 38 & 1596 \\
\hline
\end{tabular}

*For most of these subjects, the parents are first cousins; some of them are, in addition, related through a distant common ancestor, so their inbreeding coefficient is slightly more than 0.0625 .

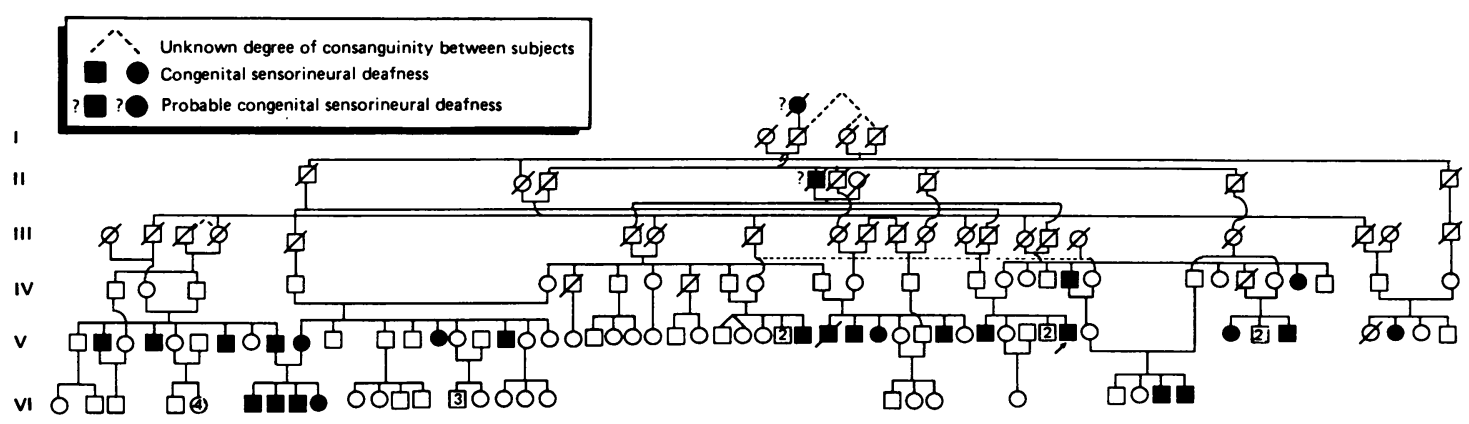

Figure 3 An example of a pedigree with numerous cases of congenital sensorineural deafness. 
Table 3 Geographical distribution of all affected cases in the 14 districts of the governorate of Nabeul.

\begin{tabular}{lrrrrr}
\hline & \multicolumn{2}{c}{ Place of residence } & & \multicolumn{2}{c}{ Origin of parents } \\
\cline { 2 - 3 } \cline { 5 - 6 } District & No & $\%$ & & No & $\%$ \\
\hline$(1)$ & 27 & $20 \cdot 9$ & & 31 & $24 \cdot 8$ \\
$(2)$ & 8 & $6 \cdot 2$ & & 6 & $4 \cdot 8$ \\
$(3)$ & 15 & $11 \cdot 6$ & & 16 & $12 \cdot 8$ \\
$(4)$ & 16 & $12 \cdot 4$ & & 18 & $14 \cdot 4$ \\
$(5)$ & 7 & $5 \cdot 4$ & & 6 & $4 \cdot 8$ \\
$(6)$ & 1 & $0 \cdot 8$ & & 1 & $0 \cdot 8$ \\
$(7)$ & 10 & $7 \cdot 8$ & & 4 & $3 \cdot 2$ \\
$(8)$ & 6 & $4 \cdot 7$ & & 2 & $1 \cdot 6$ \\
$(9)$ & 7 & $5 \cdot 4$ & & 8 & $6 \cdot 4$ \\
$(10)$ & 4 & $3 \cdot 1$ & & 9 & $7 \cdot 2$ \\
$(11)$ & 12 & $9 \cdot 3$ & & 15 & $12 \cdot 0$ \\
$(12)$ & 3 & $2 \cdot 3$ & & 2 & $1 \cdot 6$ \\
$(13)$ & 8 & $6 \cdot 2$ & & 2 & $1 \cdot 6$ \\
$(14)$ & 5 & $3 \cdot 9$ & & 5 & $4 \cdot 0$ \\
Total & 129 & & & 125 & \\
\hline
\end{tabular}

The frequency of subjects whose parents are first cousins (inbreeding coefficient $\mathrm{F}=0.0625$ ) is $\mathrm{c}=0.605$ $(23 / 38)$ in probands and $c^{\prime}=0.287(458 / 1596)$ in controls; thus the relative increase is $2 \cdot 11$. If we assume genetic homogeneity of the disease, we can use Dahlberg's formula ${ }^{7}$ (which is the most appropriate when the proportion of marriages between first cousins is far from the value expected under random mating) to estimate the deleterious gene frequency q:

$$
c=c^{\prime}(1+15 q) /\left[16 q+c^{\prime}(1-q)\right] .
$$

This leads to an estimate of $q$ of $0 \cdot 02$. Assuming, with Dahlberg, that the frequency of marriages is not far from panmixia when parents are not first cousins, we can write the prevalence $f$ as:

$$
f=c^{\prime}\left(q / 16+15 q^{2} / 16\right)+\left(1-c^{\prime}\right) q^{2}=0 \cdot 0009 .
$$

The geographical distribution of all affected subjects is given in table 3 . In general, the origin of parents was the same as the place of residence; the parents had migrated from another governorate in only four cases out of 129 . There were five districts with a particularly high number of cases: Hawaria, Menzel Temime, Klibia, Grombalia, and Bouargoub. These areas represent the place of residence of 70 cases and the origin of parents of 80 cases. The exact localisation of the villages from which the parents originated showed four clusters, represented on the map and denoted A, B, C, and D (fig 2). Two clusters, $\mathrm{A}$ and $\mathrm{B}$, are particularly important since they represent, respectively, $51 \%(64 / 125)$ and $34 \%$ $(43 / 125)$ of cases. In the district of Hawaria one section (hatched on the map) contains $22 \%(28 / 125)$ of all cases. In these two clusters, all the affected subjects came from rural areas known to be endogamous in previous generations.

\section{Discussion}

The prevalence of sensorineural profound deafness with no associated abnormalities has been estimated to be 7/10 000 in the governorate of Nabeul. This estimate was obtained through the estimation of the probability of ascertainment $\pi$. This parameter was estimated using the distribution of probands among affected sibs in multiplex sibships. This method assumes that probands have been independently ascertained, ${ }^{5}$ which may not be true since there were only two sources of data in this particular sample. There were four sibships with two probands. In one case, the probands were dizygotic twins and could not be considered to be independently ascertained, so only one proband was counted. In the three other cases, the probands were ascertained through the same source: in two sibships through the hospital, and in the third through a school for deaf children. It is very difficult to know if ascertainment is really independent, since there is a high probability that an affected child is followed in the same department as his affected sib, and also a high probability that two affected sibs go to the same school. So, the $\pi$ estimate of 0.20 is probably an overestimate of the true value. The consequence is that the prevalence is probably underestimated, but this bias may be negligible considering the large confidence interval.

The overestimation of the probability of ascertainment should also theorectically affect the segregation frequency estimate. However, Martinez et $a l^{8}$ showed that an overestimation of $\pi$ has a negligible effect on $p$ when $\pi$ is low, which is the case in our sample.

There are now complex methods of segregation analysis, the basic aim of which is to provide evidence for a major gene among several sources of familial aggregation. The method using the 'unified' model,' for instance, is in favour of a major gene in numerous examples. These methods are not appropriate to this disease where the existence of a major gene is not in doubt and where the problem is to know if a simple recessive model can explain the data. Furthermore, these methods assume a panmictic structure of the population and genetic independence of parents, which is not the case in the present data. The incorporation of a coefficient of kinship between parents and of the possibility of a non-panmictic structure of the population into the POINTER program ${ }^{10}$ is under study at present.

We have seen that the data in most categories of sibships perfectly fitted a simple recessive model with complete penetrance and no sporadic cases. Only in the category of sibships with one affected parent married to his/her first cousin was an excess of affected children observed. However, this excess was the result of only one sibship with three out of three children affected and can be attributed to chance.

The recessive hypothesis is strengthened by the increase in the inbreeding coefficient of the probands 
compared to that of the controls. The relative increase in the frequency of probands whose parents are first cousins compared to controls allowed an estimation of the deleterious gene frequency of 0.02 , assuming homogeneity of the disease. This assumption would be unrealistic in European countries where there are probably several loci for autosomal recessive profound congenital deafness. The population of the governorate of Nabeul is likely to be more homogeneous, but the possibility that more than one locus is involved must be kept in mind. The fact that the estimate of the prevalence, 0.0009 , obtained under this assumption is close to the estimate of 0.0007 obtained by the first method, although both estimates have large confidence intervals, can be considered as an argument for genetic homogeneity of the disease in this region of Tunisia.

Four clusters have been found by studying the origins of the parents of affected cases. Two of them are particularly important because they include $85 \%$ of cases. The fact that these clusters have been found in areas known to be highly endogamous in the past can explain these aggregations in two ways. First, the socioeconomic isolation of these groups may have led to an increase in gene frequency in some of them, owing to genetic drift. This phenomenon is now well known and the high frequency of hearing loss observed in an isolated West Indies population could be attributed to genetic drift as well as founder effect. ${ }^{11} 12$ Second, although the mean inbreeding coefficient has substantially decreased, it remains high enough to maintain a high frequency of homozy- gotes. In the control population of these areas, the mean inbreeding coefficient is 0.0283 for persons aged over 20 years and 0.0163 for those aged less than 20 years.

We are grateful to Dr $\mathrm{H}$ Marrakchi for his help and cooperation in this study and to M C Babron for revision of the manuscript.

1 Fraser GR. The causes of profound deafness in childhood. Baltimore: Johns Hopkins University Press, 1976.

2 McKusick VA. Mendelian inheritance in man. Catalogs of autosomal dominant, autosomal recessive, and $X$-linked phenotypes. 8th ed. Baltimore: Johns Hopkins University Press, 1988.

3 Ben Arab S, Chalbi N. Estimation par maximum de vraisemblance appliquée à l'analyse génétique de la surdi-mutité dans les populations humaines (Nord de la Tunisie). Rev Fac Sc Tunis (Tunisie) 1984;3:235-49.

4 Barrai I, Mi MP, Morton NE, Yasuda N. Estimation of prevalence under incomplete selection. Am $\mathcal{F}$ Hum Genet $1965 ; 17: 221-36$.

5 Morton NE. Segregation analysis in human genetics. Science 1958;127:79-80.

6 Morton NE. Genetic tests under incomplete ascertainment. Am f Hum Genet 1959;11:1-16.

7 Dahlberg G. Mathematical methods for population genetics. Basel: Karger, 1948.

8 Martinez M, Bonaïti-Pellié C, Clerget-Darpoux F. Effects of misspecifying the ascertainment model in segregation analysis. Genet Epidemiol (submitted).

9 Lalouel JM, Rao DC, Morton NE, Elston RC. A unified model for complex segregation analysis. Am $\mathcal{f}$ Hum Genet 1983;35:816-26.

10 Lalouel JM, Yee S. POINTER: a computer program for complex segregation analysis with pointers. Technical report. Population Genetics Laboratory, University of Hawaii, Honolulu, 1980.

11 Bonaïti C, Demenais F, Bois E, Hochez J. Studies on an isolated West Indies population. IV. Genetic study of hearing loss. Genet Epidemiol 1986;3:113-9.

12 Bois E, Bonaïti C, Lallemant M, et al. Studies on an isolated West Indies population. III. Epidemiologic study of sensorineural hearing loss. Neuroepidemiology 1987;6:139-49. 